\title{
LA ETNICIDAD COMO UN ARMA IDEOLÓGICO-RELIGIOSA EN LA ANTIGUA GRECIA: EL CASO DEL MONTE LICEO
}

\author{
ETHNICITY AS AN IDEOLOGICAL AND RELIGIOUS WEAPON IN \\ ANCIENT GREECE: THE CASE OF MONTE LICEO
}

$\mathrm{M}^{\mathrm{a}}$ CRUZ CARDETE DEL OLMO*

\begin{abstract}
Resumen: La identidad es una forma de autodefinición necesaria para la constitución de cualquier grupo humano. Algunas sociedades necesitan llevar más allá sus procesos identitarios desarrollando, a través de poderes políticos consolidados, sentimientos étnicos de mayor calado ideológico que los identitarios. El paso de la identidad a la etnicidad no es ni obligado ni sencillo, como ilustra el ejemplo elegido, el Monte Liceo, en Arcadia, claro exponente de la fuerza ideológica que alcanzan las definiciones identitarias y los procesos de construcción étnica.
\end{abstract}

Palabras clave: Identidad. Etnicidad. Monte Liceo. Megalópolis. Arcadia.

\section{IDENTIDAD Y ETNICIDAD}

El término "grupo étnico" comenzó a generalizarse a principios del s. XX para soslayar de ese modo las connotaciones peyorativas del término "raza", trasladadas a la arqueología especialmente a través de la obra de Kossinna y sus seguidores (Siapkas 2003: 12; Jones 1997: 16). Durante un tiempo se pensó que el término iría perdiendo fuerza, ya que la instauración de regímenes complejos, democráticos, industrializados y dominados por los medios de comunicación haría inútil la existencia de los sentimientos étnicos como forma de identidad social. Madrid

* Investigadora Juan de la Cierva, Universidad Complutense de

\begin{abstract}
Identity is a necessary way of auto-definition in the process of building any human group. Some societies (not many) with strong political forces need to develop their identity process and to build the most powerful ethnic feelings. The building of ethnicity is not a simply task, as can be seen in the case of Mount Lykaion, in Arcadia. This is a clear example of the ideological power which characterizes the identity definitions and the ethnic building process.

Key words: Identity. Ethnicity. Mount Lykaion. Megalopolis. Arkadia.
\end{abstract}

Sin embargo, lejos de desaparecer, los grupos étnicos se han hecho más fuertes y han elevado sus reivindicaciones a las más altas esferas. La importancia que se les otorga en nuestra sociedad ha conllevado una eclosión de los estudios sobre la etnicidad en el pasado.

Nuestro término etnia deriva del griego ethnos. Ahora bien, sería un error equiparar ethnos con etnia y ello, a mi juicio, por dos razones.

En primer lugar, las barreras analíticas de la etnicidad, como las de toda ideología, son confusas (Duke 1998: 119). Precisamente debido a su mutabilidad y variabilidad constante, es muy complejo definir la etnicidad y, cuando lo hacemos, empleamos nuestros propios referentes sociales, distintos por completo a los de otras sociedades. Como en su momento señaló Eriksen (1993: 16), 
buscar la etnicidad supone no sólo encontrarla sino también construirla. Cuando hablamos de la etnicidad en el mundo griego no lo estamos haciendo del ethnos de Aristóteles, Heródoto o Tucídides, sino de nuestro propio concepto de etnia, reconvertido en frontera arbitraria del fenómeno antiguo (Renfrew 1998: 277).

En segundo lugar, el término griego ethnos responde a una realidad infinitamente más multiforme que la que reconoce nuestro moderno etnia, pudiendo ser empleada por el mismo autor para definir variadas situaciones humanas y/o sociales. De forma genérica, ethnos definía en el mundo griego un grupo cuyas características internas le permitían diferenciarse de otros, estuviese formado por dioses ${ }^{1}$, personas ${ }^{2}$ o animales ${ }^{3}$. Aplicado al mundo de la política, el ethnos no alcanza una mayor concreción, ya que podía designar desde a los habitantes de una polis ${ }^{4}$ a comunidades socialmente más simples que la ciudad estado ${ }^{5}$, pasando por grupos de poleis unidos bajo un signo común (el ethnos arcadio, por ejemplo) o un pueblo extranjero con cierta cohesión organizativa ${ }^{6}$. El ethnos no describe a una entidad similar a nuestra etnia hasta las Guerras Médicas y, aún entonces, su contenido será diferente del que tendrá durante la Guerra del Peloponeso, el otro momento puntero de empleo del término bajo parámetros similares a los nuestros (Cardete 2004b).

Puede decirse que las Guerras Médicas fueron un período álgido de la exaltación étnica griega ${ }^{7}$. Por primera vez se percibe cierta unidad de las independientes poleis griegas contra un enemigo común, extranjero, al que se anatemiza con todos los vicios posibles, destacando sobre todos ellos su tendencia a la tiranía frente al irrefrenable amor por la libertad que se jactaban de poseer los griegos ${ }^{8}$. No se puede acusar a Heródoto de ser especialmente etnocéntrico (al menos, no en comparación con otros autores de la misma época) y, sin embargo, su definición del ethnos griego, motivada por el enfrentamiento greco-persa, es marcadamente tradicional y excluyente puesto que lo que señala la helenidad para Heródoto ("la consanguinidad y la comunidad de lengua, de creencias religiosas, de ritos sacrificiales,

\footnotetext{
1. Esq. Filoc. 1147.

2. Hom. Il. II, 91; III, 32; VII, 115; XI, 724; Pind. Ol. I, 66; P.

3. Hom. Il. II, 87 y 469; Sof. Eumen. 366

4. Hdt. VIII 144.

5. Aristot. Pol. III 1285 B; V 1310 A; VII 1327 B y 1336 A ;

6. Aristot. Pol. I 1257 A; VII 1324 B.

7. Extensa bibliografía sobre el tema en Cardete (2004); Cartledge (1993: 33-62); Hall (1989); Hall (1997 y 2002); Hartog (1980), etc.

8. Esqu. Pers. 181-199 y 584-594; Hdt. VII, 136; Plat. Leyes
} IV, 252 VIII 1338 B. III 693 c-698 a.

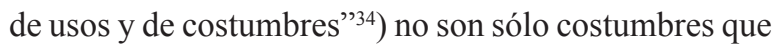
puedan aprenderse, sino elementos, como la consanguinidad, que vienen dados por el nacimiento.

Ahora bien, ni todas las poleis aceptaron la unión contra el extranjero, ni se sintieron identificadas con las proclamas étnicas espartanas y, sobre todo, atenienses, que se quisieron hacer pasar por "griegas" a través de la exaltación de una genealogía común que incluía a todos los griegos en una misma red de parentesco ${ }^{9}$, siendo el parentesco una de las bases clave de la organización étnica (Emberling 1997: 300-306). El conato de sentimiento étnico no cuajó y ello se demostraría años después, cuando la Guerra del Peloponeso rellenó de un significado diferente al término ethnos. Ya no se trataba de una oposición griegos-bárbaros (de hecho, Esparta no dudó en pedir y aceptar la ayuda persa contra los atenienses) sino de una confrontación dorios-jonios, cada uno con sus propias genealogías que los separaban. Los argumentos que excluían al contrario fueron, eso sí, muy similares.

Otro momento crucial de la definición étnica que demuestra hasta qué punto su uso era interesado lo encontramos a finales del $\mathrm{s}$. V y principios del IV. Isócrates (436-338), a la cabeza de un grupo de oligarcas preocupados por la creciente amenaza de una revolución política que supusiera la confiscación de sus tierras y su posterior redistribución entre los griegos pobres, clamó por la conquista de gran parte del imperio persa para tomar revancha de los sacrilegios cometido por los hombres de Jerjes en el 480-479, vengándose así también de la humillante Paz del Rey (386 a. C.) que, al devolver a las ciudades griegas de la Jonia al control persa, coartaba las posibilidades de expansión atenienses. Creando un enemigo pretendían llevar la guerra fuera de casa. En sus discursos Isócrates emplea un modelo de definición étnica que desprecia la exclusión y aboga por el proceso contrario. Para él "son llamados helenos no aquellos que tienen nuestro mismo origen, sino aquellos que tienen en común con nosotros nuestra cultura" ${ }^{37}$. Isócrates defendía que sólo Filipo sería capaz de devolverle a Atenas el esplendor perdido y convertirla en cabeza victoriosa de la nueva oposición anti-persa, pero para eso necesitaba primero convencer a sus conciudadanos de que Filipo, a pesar de pertenecer a la casta macedonia, que en el imaginario colectivo ático no era griega, sino bárbara, era realmente uno de ellos. Eliminando la barrera de la consanguinidad y la tierra materna y cargando las tintas sobre la conducta (que puede aprenderse y, por lo tanto, adquirirse) Filipo pasaba a ser un mecenas digno de la helenidad ática, lo cual no significaba que lo fueran

9. Magnífico análisis sobre las genealogías griegas en Hall (1997 y 2002). 
también el resto de macedonios, sino sólo aquellos que se comportaran como si fueran griegos. Es lo que, en una expresión bastante irónica, Paul Cartledge (1993: 45) califica como "el síndrome de algunos de mis mejores amigos son judíos".

El ethnos, por tanto, no responde a una realidad fija, sino que se basa en un concepto abstracto de unidad y cohesión, es decir, en un sentimiento de "identidad", que tanto vale para definir abejas como sociedades humanas, a persas que a dorios o jonios, dependiendo del contexto y los intereses.

Nuestra etnia, sin embargo, es un concepto mucho más concreto que va más allá de la identidad. Muchos grupos reconocen sentirse unidos por una identidad común que colma su necesidad de pertenencia (las tribus urbanas, por ejemplo) pero no por ello llegan a constituirse en etnia ya que no desarrollan ni lazos de parentesco ni territorialidad. Por tanto, en mi opinión, habría que diferenciar entre la necesidad humana de pertenencia e inclusión, intrínseca al ser humano, y la construcción de un grupo étnico, proceso este último que precisa de un poder político que dé forma, fomente y sostenga el sentimiento étnico-genealógico y territorial, adecuándolo a los diferentes momentos por los que pasa la comunidad y a los grupos sociales e individuos que la forman. Lejos del estatismo, el sentimiento étnico cambia con la sociedad que lo construye y tanto en lo referente al presente y las formas de canalización de la etnicidad como respecto al pasado.

La etnicidad no despierta la conciencia de pertenencia a un grupo, sino que la crea. Un grupo étnico cuenta con una serie de hitos históricos que todos sus miembros reconocen como comunes e implicadores, pero en su bagaje también existen muchos olvidos y ausencias compartidos. Tanto los unos como los otros son modificados desde el presente conforme a los intereses en juego. Los lapones, por ejemplo, juegan con su identidad según sus conveniencias: la ocultan, adoptando la noruega en situaciones discriminatorias para ellos, y la enfatizan como diferente y única en momentos favorables (Eidheim 1976). No obstante, quienes reivindican su pertenencia a un grupo étnico no aceptan en absoluto su construcción desde el presente, sino su perennidad en el tiempo, y dicha convicción forma también parte del fenómeno étnico. Como señala Hall (1997: 19), negar la existencia de la etnicidad no aplaca el problema, sino que lo aviva ${ }^{10}$. Mientras la comunidad crea

10. "If there is anything to be learnt from the recent ethnic conflicts throughout the world, it is that the refusal to recognise ethnicity is more likely to exacerbate than to eliminate its potency" (Hall 1997: 19). en la realidad del pasado reinventado poco importa si "realmente" ocurrió o no (Hall 2002: 15-16; Anderson 1991: 6).

Ahora bien, ¿por qué la identidad se transforma en etnicidad y cómo lo hace? Para lograr la cohesión que necesita un grupo étnico hay que contar con situaciones propicias y con mecanismos de control específicos que prueben a los ojos de la comunidad que dicha etnicidad existe.

El enfrentamiento, la escasez y la oposición son los elementos claves de una sociedad que comienza a definirse como étnica. De hecho, la mayoría de los antropólogos que han escrito sobre la organización étnica lo han visto en el contexto de la competición por los recursos y muchos la han entendido como un medio de lograr intereses particulares o de maximizar valores (Jones 1997: 69-75; Jenkins 1997: 10; Prontera 2003: 110). La etnicidad sólo se percibe en la relación con otros, pues es un modo de interactuar con ellos. En ocasiones, las relaciones interétnicas son pacíficas pero generalmente se trata de situaciones violentas (guerras, competición por los recursos, sometimiento...). Sean positivas o, mucho más frecuentemente, negativas las circunstancias en las que se desarrolla la conciencia de diferencia étnica, ésta nace por contraste con el exterior, como modo de marcar la oposición a otros. El concepto de "yo" sólo se perfila en relación con el del "otro". A un nivel de grupo, si no hay un oponente no existe la necesidad de definir lo que somos, porque nuestra existencia es la única que tiene sentido para nosotros, luego nosotros somos el mundo. La negación es, pues, un arma eficaz de oposición ya que va más allá de la diferencia para alcanzar el máximo grado de enfrentamiento posible (Cartledge 1993: 11).

Dicho sentimiento de oposición sólo puede ser canalizado hacia una formación étnica si existe un poder político lo suficientemente consolidado como para fomentar la identidad y cohesionarla hasta transformarla en etnicidad. Por lo tanto, la etnicidad no es un proceso natural, intrínseco al desarrollo social, sino un proceso político que necesita de un centro director que lo promueva y sostenga (Cardete 2005 ${ }^{\mathrm{a}}$ : 59-63).

A esto hay que añadir que el poder de la adscripción étnica, su fuerza identitaria y definidora, al igual que la de la religión, se basa en dos principios. En primer lugar, la etnicidad ofrece respuesta a las grandes preguntas sobre la existencia humana (quiénes somos, hacia dónde nos dirigimos y por qué estamos aquí). Creo, de hecho, que la base de la conciencia étnica es la necesidad de sentirse uno con el grupo, lo que generalmente conduce a una oposición con quienes no forman parte de él, ya que la exclusividad refuerza los lazos de 
pertenencia que parecen necesarios al ser humano (Vos 1982: 17). En segundo lugar, la etnicidad es una de las armas más poderosas, junto con la religión, para justificar la desigualdad social y la jerarquización de poder. La diferencia con la religión es que la justificación de la diferencia procede de un orden social, de una estructura humana que, aunque esté conectada con los deseos de los dioses, no emana directamente de ellos, como sí lo hacen los preceptos religiosos. Aunque la relación entre la etnicidad y el rango en una sociedad no es directa (el género, la clase, la edad y otros criterios que varían de sociedad en sociedad contribuyen también a la definición del status de un individuo dentro de su comunidad), las ideologías étnicas suelen justificar la jerarquización social. En muchas sociedades étnicas se detecta una alta correlación entre la identidad étnica y la posición social (Eriksen 1993: 51; Eidheim 1976: 50-51). Es el caso, por ejemplo, de los Naga indios. Una de las características que los define como grupo es la transformación de algunos de sus miembros en tigre, adoptando la fuerza y astucia propias de este animal. Dicha metamorfosis se entiende como un privilegio que sólo afecta a las clases altas, de modo que funciona como un modo de distinción social o marginalidad positiva (Ovensen 1983: 16-17).

El modo de promover y sostener la etnicidad es demostrar su existencia con pruebas que la comunidad considere irrefutables. Dichas pruebas, que nos permiten a nosotros reconocer la etnicidad y a los pueblos del pasado creer en ella, son los llamados indicios y criterios de etnicidad. No se trata de reglas fijas que se puedan extrapolar a todas las sociedades (lo cual nos haría caer en posturas primordialistas) sino de categorías de análisis necesarias para definir nuestro objeto de estudio. Por esto creo injusta la hipótesis de Siapkas (2003: 14-15; 41-46), según la cual el uso de criterios e indicios presupone cierta aceptación de las posturas esencialistas. No es este, desde luego, el caso de quien escribe.

Los indicios de etnicidad son aquellos elementos empleados con cierta frecuencia por las sociedades para autodefinirse. Su existencia, no obstante, es azarosa y no es por sí misma una prueba determinante de que la sociedad haya decidido reconocerse como una etnia. Entre dichos indicios destacan tres: una lengua y una cultura común y una religión compartida. Ninguno de estos tres indicios es fácil de aprehender, pues sus límites no pueden trazarse con precisión y cada sociedad los asimila y los prioriza de modos distintos. Su contextualización es tan variada que no pueden emplearse como criterios generalizadores (Hall 1995a: 9 y 1998: 266; Jones y Graves-Brown 1996: 7; Pascual González 2001: 243; Park 1994: 154).
En cuanto a los criterios de etnicidad, podemos hablar de dos: el reconocimiento de ancestro/s común/es, base del sistema étnico, y la referencia a una tierra materna (Hall 1998: 266; Eriksen 1993: 12 y 68; Smith 2000: 65; Shennan 1994: 14). En Grecia, las genealogías articulan descendencia, parentesco y territorialidad y sirven para pensar sobre la propia existencia, sobre la autodefinición (Hall 2002: 20-89). La religión funciona como un arma ideológica que canaliza los sentimientos étnicos a través de formulaciones mitológicas. Grupos como los dorios o los jonios basan su adscripción en un parentesco compartido que se define por dos puntos de referencia, ambos de carácter mítico-religioso: la existencia de una tierra madre y la presencia de héroes epónimos.

Por un lado, cuentan con un territorio primordial que en el caso de los dorios se sitúa en Doris y en el caso jonio cambia, encontrándose primero en Asia Menor y luego, movido por intereses atenienses, en el Ática (Alty 1982: 8; Hall 2002: 204). Los mitos de origen reivindican, por tanto, territorios primordiales que están en la base de la constitución territorial de las sociedades pero que van más allá de ella, ya que los territorios de los grupos étnicos no son sólo físicos sino, sobre todo, sociales y mentales (Eriksen 1993: 39).

Por otro lado, las diferentes genealogías se basan en la existencia de los héroes epónimos que dan nombre y ascendencia a los grupos étnicos. Así, los dorios se proclamaron descendientes de Doros mientras que los jonios hacían lo propio con Ión. La religión, en este y otros casos, canaliza la reivindicación étnica otorgándole unas bases férreas sobre las que asentarse (Malkin 1998: 6).

Una vez limitados los campos de la etnicidad hay que preocuparse sobre cómo analizarla. Desde el punto de vista ontológico existen dos modos de afrontar dicho análisis (Hall 1997: 17-19; Jones 1997: 65-82; Eriksen 1993: 54-58; Siapkas 2003: 41-46 y 175-195): los primordialistas consideran que es un fenómeno humano que se evade de los contextos históricos; los instrumentalistas, por el contrario, sostienen que la etnicidad es un constructo social y que, como tal, responde a las necesidades de cada grupo humano y varía conforme estas van cambiando. La adopción de uno u otro modelo ontológico implica generalmente el empleo de diferentes técnicas de estudio. Mientras que los primordialistas prefieren un análisis que siga los principios antropológicos de la categoría etic, basados en el observador, los instrumentalistas, partiendo del modelo social constructivista de la obra de Barth (1976: 11-12; Pascual González 2001: 241) defienden que pertenecer a un determinado grupo étnico es un categoría de adscripción 
emic, ya que viene definida por la decisión del individuo de calificarse y definirse como tal y no por las ideas preconcebidas del observador (Eriksen 1993: 11). A pesar de que, en mi opinión, los instrumentalistas se acercan mucho más a las causas y consecuencias de la formación y extensión del fenómeno étnico, por todo lo ya expuesto, es cierto que algunas de las posturas que pueden encuadrarse bajo esta denominación común (la opción esencialista es mucho más homogénea) se caracterizan por un excesivo normativismo biológico que, en ocasiones, puede derivar en un reductor determinismo biológico. Además, la adopción de una visión emic para el análisis antropológico o etnohistórico no deja de presentar problemas teórico-metodológicos, ya que defender en nuestros días, imbuidos de espíritu postmoderno, que el observador puede evadirse de su propia cultura, tradición y personalidad para analizar objetivamente al observado no deja de ser una utopía, peligrosa además de falaz. En un intento de aunar ambas tradiciones, pero con una base instrumentalista, y limar los aspectos debatibles de la una y la otra, han surgido interesantes trabajos como los de A. D. Smith (1986 y 2000), centrado en el surgimiento de las nacionalidades modernas.

El estudio de la etnicidad en el pasado, en este caso del mundo griego, añade problemas a los debates, ya que supone reconocer la etnicidad a través de los registros arqueológicos e históricos de pueblos extintos. Hall dio el pistoletazo de salida al estudio de la etnicidad en el mundo antiguo con su ya célebre Ethnic identity in Greek antiquity. Su postura sobre la labor del arqueólogo en el terreno de los estudios étnicos levantó mucha polvareda, ya que afirmó con rotundidad que la cultura material no era un referente válido para reconocer grupos étnicos (Hall 1997: 3) ${ }^{11}$. La reacción de los arqueólogos no se hizo esperar, destacando la obra de S. Jones, The archeology of ethnicity: constructing identities in the past and in the present, otro clásico de los estudios sobre la etnicidad en arqueología.

Ante la polémica levantada ${ }^{12}$ el propio Hall matizaría más tarde sus ideas arguyendo que la arqueología está capacitada para detectar rasgos culturales que pueden ser considerados étnicos, aunque necesita de las fuentes literarias para cerciorarse de que pertenecen a un etnia (Hall 2002: 24). Argumento reversible, obviamente, ya que las fuentes literarias también necesitan de la arqueología para enriquecerse (Emberling 1997:

11. "While material symbols can certainly be selected as active emblems of a consciously proclaimed ethnic identity, it is a mistake to assume that material cultural patterning can serve as an objective or passive indication of ethnic groups" (Hall 1997: 3).

12. Algunos de los hitos de dicha polémica se pueden ver en Jones (1997 y 1998), Morris (1998) ...
311). Si la etnicidad se entiende como un instrumento ideológico de definición social, tiene que verse reflejada en el registro arqueológico. Su carácter abstracto se concretiza en acciones y producciones que son útiles para la sociedad, ya que le permiten excluir de ella a quienes le interesa presentar como enemigos. La cultura material también crea identidad (Morris 1998: 270; Jones 1997; Morgan 1991-1992: 134), sea a través de producción cerámica, visibilización de fronteras, construcción de santuarios, manipulación física de lugares sacros, etc., como trataré de demostrar en el caso concreto del Monte Liceo y la comunidad parrasia. La arqueología ofrece, por lo tanto, una oportunidad para el análisis de los símbolos étnicos y de aquellas prácticas culturales que dan forma a la construcción discursiva de la identidad en el pasado (Jones 1998: 273; Renfrew y Meskell 2001: 26). Por supuesto, la relación entre cultura material y etnicidad resulta problemática, pero no más ni menos que cualquier otra formulación simbólica, como la religiosa.

Pasemos ahora al análisis de un ejemplo concreto, el del Monte Liceo, en Arcadia, que ilustre como identidad y/o etnicidad fueron empleadas como armas ideológico-religiosas en la Antigua Grecia.

\section{IDENTIDAD Y RELIGIÓN: EL CASO DEL MONTE LICEO}

En el año 369 a. C. tuvo lugar el sinecismo de Megalópolis. A costa de los territorios y poblaciones de la Parrasia y la Menalia se fundó una nueva ciudad que albergaba pretensiones expansionistas y panarcadias. Megalópolis se presentó como la imagen de una nueva Arcadia unida, proyecto que nunca llevó a cuajar ni en su dimensión política ni, mucho menos, en sus implicaciones étnicas. No obstante, las elites megalopolitanas utilizaron hábilmente la propaganda política para atribuirse un pasado del que carecían pero que necesitaban para justificar su existencia. Dicha propaganda pasó por el uso, manipulación, reelaboración y construcción de símbolos religiosos con carga identitaria, es decir, de símbolos que explicaran a las poblaciones obligadas a formar parte del sinecismo y a aquellas otras que, ajenas al mismo, lo contemplaban con preocupación, el porqué de la nueva ciudad, las razones ancestrales que explicaban su repentino nacimiento. Megalópolis, erigida en motor del movimiento étnico, en núcleo de irradiación de los sentimientos identitarios, jugó con maestría sus cartas y consiguió convertir a la frontera suroeste y, especialmente, a la Parrasia, con el Monte Liceo como estandarte, en un verdadero icono, 
un paisaje cultural tan rico que hasta nosotros ha llegado su influencia en la formación de una imagen de Arcadia. Pero fracasó al pretender construir una etnicidad arcadia porque pretendió hacerlo por imposición en vez de por convencimiento.

Megalópolis llegó a controlar, directa o indirectamente, un área que abarca unos $1500 \mathrm{~km}^{2}$, ocupando prácticamente todo el centro y sur de Arcadia. Se trata de una superficie dominada por los cursos del Alfeo y sus afluentes, así como por las estribaciones rocosas que marcan sus límites y entre las que destaca, en el extremo oeste, la cadena montañosa del Cotilo, al que pertenece el Monte Liceo. Esta cadena constituye el límite oeste del territorio megalopolitano y hace frontera con la polis de Figalía, que también tuvo al Cotilo como imagen identitaria (Cardete 2005a: 75-125). La interrelación cultural y sacra de esta cadena montañosa es importantísima, pues es ella la que proporciona la unidad simbólica al paisaje y convierte la frontera suroeste en un complejo perceptivo tan útil para construir identidad (Fig. 1).

Precisamente es al extremo suroeste del territorio de Megalópolis al que se circunscribe la Parrasia, el corazón simbólico y demográfico de la nueva "capital", ya que la Parrasia proporcionó no sólo una gran parte del territorio y de la población de la nueva ciudad sino también, y especialmente, buena parte del entramado mítico que permitiría a los megalopolitanos construirse el pasado que necesitaban para, a través de él, justificar ideológicamente su presente.

La Parrasia carece de unos límites geográficos precisos, aunque adquiere parte de su carácter específico por su situación orográfica, encajada en un paisaje de escarpados riscos.

Su organización política como tribu es un elemento cuestionable y debatible. Las fuentes de que disponemos (pocas y fraccionadas) parecen indicar que los parrasios

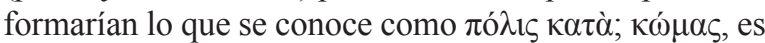
decir, una formación estatal policéntrica constituida por la agregación de varios grupos poblacionales que disponen cada uno de un territorio, una identidad y cierta autonomía, pero que reconocen otra identidad común a todos y ceden parte de su soberanía a la supracomunidad (Moggi y Osanna 2003: 418). El centro de la tribu así formada sería el Monte Liceo que, a través del culto al Zeus Liceo, aglutinó a los parrasios y les ofreció una identidad como grupo compacto.

Parrasia actúa como tribu, es decir, como organización política estatal (Nielsen 2002: 276) en cuatro ámbitos destacados: delimitación territorial, relaciones exteriores, acuñación de moneda y relaciones con santuarios panhelénicos (Cardete 2005a: 134-136).
En cuanto a la dimensión étnica de la tribu, el mito cuenta que los parrasios eran descendientes de Parrasio, hijo de Pelasgo ${ }^{13}$ lo que les convertía, inmediatamente, en autóctonos ${ }^{14}$. Con su étnico aparecen ya nombrados en la Ilíada, concretamente en el Catálogo de las $\mathrm{Na}$ ves ${ }^{15}$. Si consideramos que el Catálogo de las Naves nos ofrece la primera imagen global de Grecia, puede pensarse que este testimonio es una prueba de que las tribus arcadias, y concretamente la parrasia, existían desde épocas muy arcaicas como entidades étnicas, como defiende Roy (1972: 44). Sin entrar en un estudio exhaustivo de las tribus arcadias y sus identidades, que se escaparía del marco de este estudio, me limito señalar que hay indicios más que suficientes para sostener la tesis de que las tribus arcadias (Parrasia, Menalia, Eutresia, Cinuria, Azania y Trifilia) no se desarrollaron, como tradicionalmente se ha sostenido, dentro de un estado tribal y en época arcaica, sino que los estados tribales nacieron a partir de un grupo de poleis pequeñas que querían protegerse de la agresividad de sus vecinos. Por eso sus menciones no se hacen frecuentes hasta el s. V-IV, cuando la política interna de Arcadia alcanza un alto grado de complejidad que conlleva numerosos enfrentamientos internos (Nielsen 1996a; 1996b; 1997: 160; 2002: 271-307; Morgan 1997: 187; Cardete 2005a: 55-59). La cuestión tribal responde, por lo tanto, más a razones políticas y de supervivencia territorial que a un fenómeno de reconocimiento étnico.

Salvando, pues, el Catálogo de las Naves, las menciones a la tribu parrasia o a sus pobladores se datan todas entre los ss. V-IV, aun cuando Estrabón defienda que los parrasios, que en su época ya no existían, pues habían sido absorbidos por Megalópolis, eran uno de los ethne más antiguos de Grecia ${ }^{16}$. Es una muestra más de la fuerza propagandística de Megalópolis.

El ancestro común (el epónimo Parrasio) y la tierra materna (la propia Parrasia) son dos elementos clave de la construcción política de la etnicidad parrasia. Su encarnación fue el culto del Monte Liceo, que funcionó a modo de "santuario federal" de las comunidades que formaron el estado parrasio (Jost 1985: 183; Fougères 1904: 1434). De hecho, el Zeus Lykaios sólo aparece fuera de Arcadia en una ocasión, concretamente en Cirene hacia el 550, coincidiendo con la presencia de Demonacte de Mantinea en esta colonia para solventar su crisis social ${ }^{17}$. Dentro de Arcadia el culto se

\footnotetext{
13. Ferécides FGrHist 38 F 135 B.

14. Paus. VIII 1, 4.

15. Hom. Il. II 603-609.

16. Strb. VIII 8,1 .

17. Hdt. IV, 161-203; Diod. VIII, 30.
} 


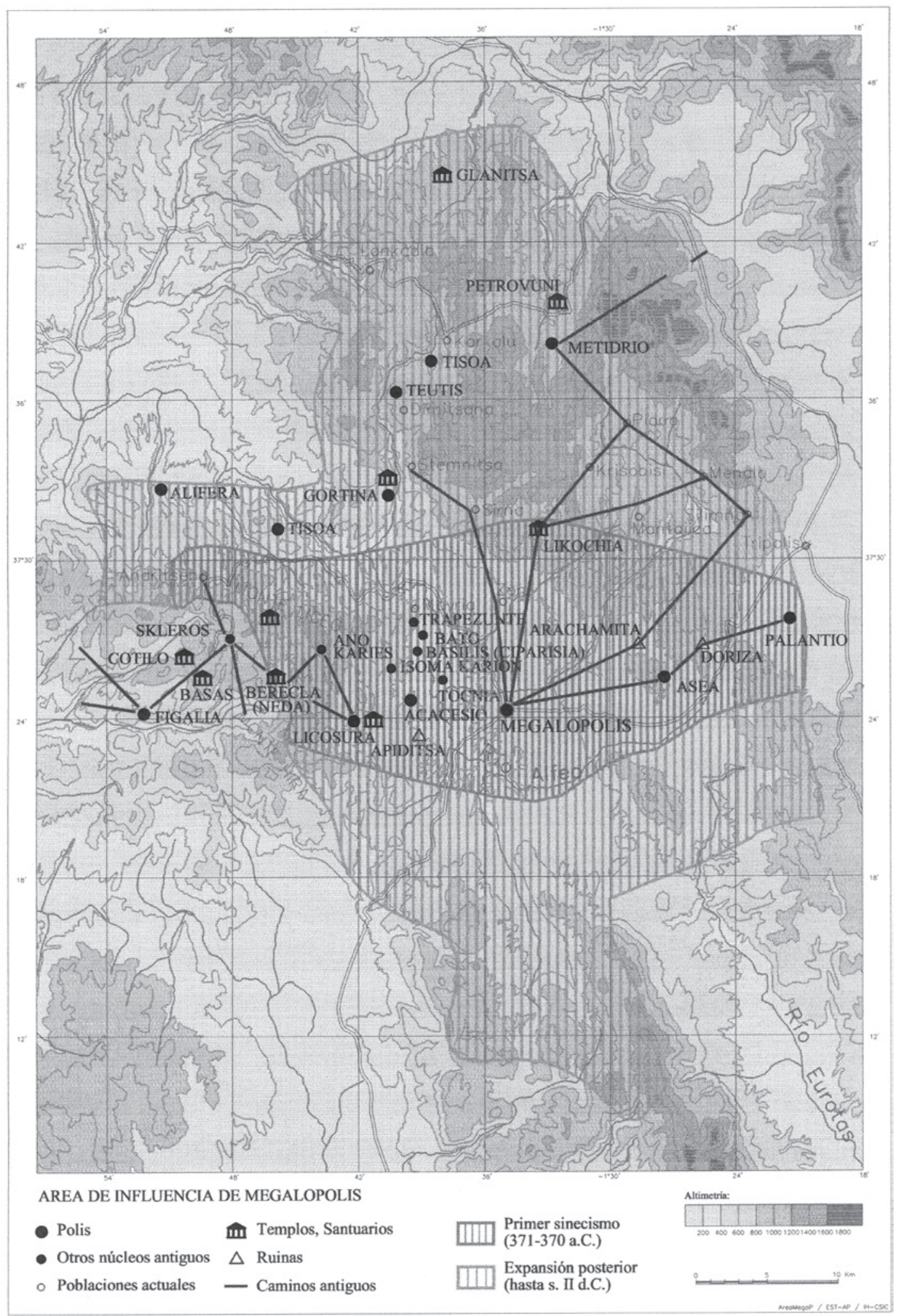

Fig. 1. Área de influencia de Megalópolis. 
circunscribe a la zona de la Parrasia (el monte Liceo y Megalópolis) y a un altar en la entrada de la puerta de Tegea en Laconia ${ }^{18}$, por lo que puede decirse que el Zeus Lykaios es una deidad típicamente parrasia.

$$
* * *
$$

El Liceo está formado por tres macizos montañosos: el pico más alto, el monte San Esteban, de 1420 m.; el monte San Elías, de 1382 m. de altitud, y un pequeño valle a $1200 \mathrm{~m}$. entre ambas cumbres llamado KatoKambos. Es entre el monte San Elías y el valle donde se encuentran las ruinas del complejo consagrado a Zeus Lykaios, aunque el monte en su totalidad gozaba de la protección y la presencia del dios.

La cumbre del monte San Elías alberga, al menos desde el s. VII (época a la que se remontan los primeros restos arqueológicos), el altar de Zeus Lykaios, desde el que se dominaba visualmente un enorme territorio ${ }^{19}$ $\mathrm{y}$, veinte metros más abajo, el temenos dedicado a este dios. La cima no contaba con ninguna construcción, simplemente con "un montón de piedras", como nos dice Pausanias $^{20}$, puesto que la sacralidad del espacio era suficiente para reconocerlo como morada del dios y núcleo identitario de la comunidad, alrededor del cual tenían lugar las Lykaia, las fiestas en las que se celebraba al Zeus lobo a través de ritos complejos entre los que se encuentran referencias a la licantropía, el sacrificio humano y el canibalismo (Cardete 2005a: 168-198). (Fig. 2.)

El salvajismo y, de algún modo, la excentricidad de estos cultos, contribuyeron a aglutinar a las comunidades parrasias alrededor de un sentimiento étnico, que les defendía como grupo de las incursiones políticas de sus enemigos. La monumentalización del complejo no fue necesaria hasta el s. IV. En este momento las necesidades parrasias pasaron a un segundo término, sustituidas por las megalopolitanas, que precisaban de la ostentación arquitectónica para expresar sacralidad. Las nuevas edificaciones marcaron una nueva dirección religiosa en el culto y una nueva forma de entender la identidad comunitaria. Megalópolis acabó convirtiendo el Liceo en la imagen étnica por antonomasia, modificando su significado.

La nueva dirección cultual que tomó el Liceo no afectó a su cima que, como antes dije, se mantuvo siempre libre de construcciones humanas, sino a la plataforma que se encuentra entre los dos picos más altos

\footnotetext{
18. Paus. VIII 53, 11.

19. Paus. VIII 38, 7 dice que desde el Liceo "se ve el Peloponeso en su mayor parte".

20. Paus. VIII 38, 7
}

del Liceo (el de San Esteban y el de San Elías), el llamado valle de Kato-Kambos. Su superficie es de 350 x 120 m., un fantástico escenario de acogida y bienvenida. La gran mayoría de las construcciones que en él se conservan datan de finales del V o en el s. IV o y se caracterizan por su funcionalidad de cara a impresionar a los visitantes. Megalópolis intentó convertir el monte Liceo en un símbolo común y para ello necesitaba visibilizarlo. La sacralidad se traslada del ojo del fiel a los edificios, a la exhibición del poder. La arquitectura del Liceo crea deliberadamente espacio con el objeto de que sea observado porque ahora el ver y ser visto se ha convertido en una necesidad de afirmación política que corre pareja a las ambiciones federales.

Megalópolis se hizo cargo del Liceo porque podía servirle como insignia y como elemento de unidad y control social a través de la creencia, pero se preocupó de modificarlo y convertirlo en el símbolo que perseguía y no tanto en el que había sido hasta entonces, utilizándolo para reafirmar la supuesta unidad étnica y proyectarla hacia el exterior, dando una idea desproporcionada de su poder. De hecho, es en el s. IV cuando el étnico Arcas se repite en las listas de vencedores de los Juegos, que hasta ese momento solían reflejar sólo la referencia a la ciudad de origen, la verdadera patris de los atletas participantes (Jost 1985: 184). La transformación de los lugares en monumentos es un modo de conservar el pasado y transformarlo al mismo tiempo (Bradley 1991: 139).

Desde el s. V y a lo largo del IV el monte Liceo se convirtió poco a poco en un lugar de peregrinación, no ya sólo para los parrasios o para los arcadios, sino también para el resto de Grecia, pues se transformó en la imagen que Arcadia proyectó al exterior, en el Olimpo arcadio, como lo llama Pausanias ${ }^{21}$. Píndaro nombra las Lykaia como unos juegos parrasios que celebraban al Zeus Lykaios ${ }^{22}$ y Jenofonte en su Anábasis relata cómo fue Jenias, el comandante arcadio, quien hizo un alto en su marcha para celebrar las Lykaia en territorio asiático $^{23}$. Sin embargo las listas de vencedores de finales del s. IV incluyen hombres de Argos, Atenas, Esparta, Macedonia, Rodas y Casandrea ${ }^{24}$, así como de Lindos y Delfos (Moretti 1953: no 23 y 35) y el Mármol Pario, ca. 294-293, considera a las Lykaia el cuarto festival más importante de Grecia y remonta su origen a los

21. Paus. VIII $38,2$.

22. Pind. Ol. IX 96 nombra a Efarmosto de Opunte, que participó en la fiesta del Zeus Liceo ante el pueblo parrasio. La fiesta vuelve a ser mencionada en $\mathrm{Ol}$. XIII, 108 y Nem. X, 48.

23. Jen. Ana. I 2, 10.

24. $I G$ V 2,549 y 550 . 
Fig. 2. Monte Liceo. Altar y temenos del Zeus Lykaios en la cima del Profeta Elías (Fotografía de la autora).

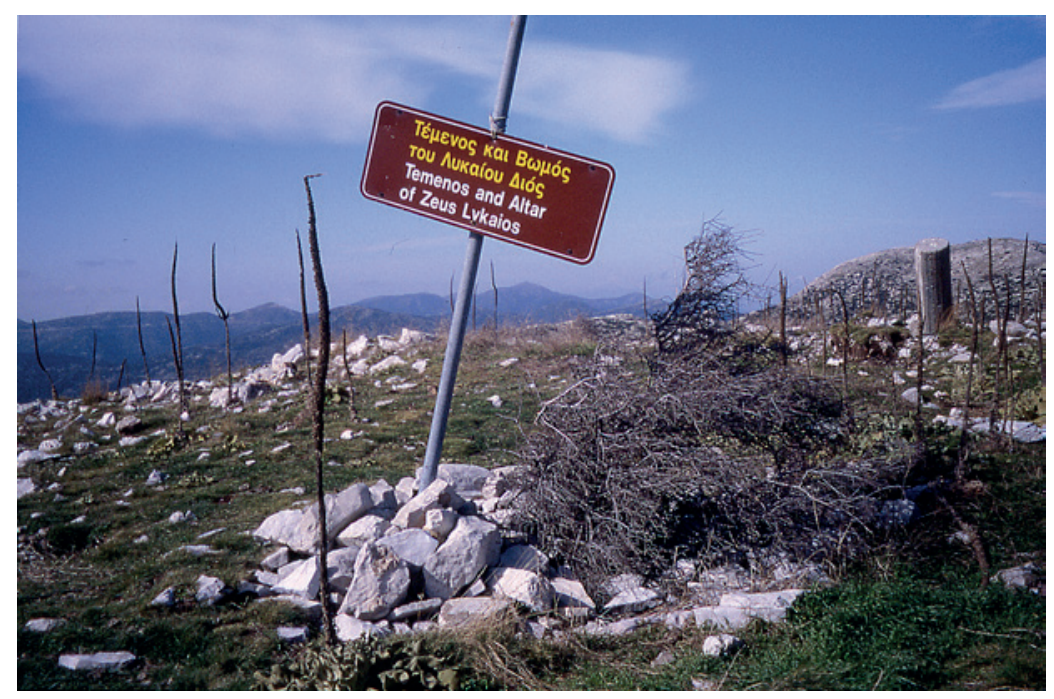

tiempos micénicos (1398-1294 a. C. $)^{25}$. Las Lykaia pasan, por tanto, de ser un acontecimiento agonístico comunitario vinculado al estado parrasio o a sus vecinos arcadios a convertirse en centro de reunión de un importante número de atletas, curiosos y espectadores y su éxito continúa durante los siglos siguientes, pues varias inscripciones agonísticas procedentes del Liceo se datan en los ss. III y II a. $\mathrm{C}^{26}$.

No obstante, los sacrificios decrecen a partir del s. IV (al menos en el registro arqueológico con el que contamos, superficial, ciertamente) y durante el III tanto la fiesta como los agones que la acompañaban se celebraron de forma discontinua, recuperándose en el 215 (Dow 1937). Todavía en época de Estrabón el santuario recibía a algunos fieles ${ }^{27}$ y con Augusto un decreto honorífico menciona a las Lykaia en conjunción con las Caisarea ${ }^{28}$. Para el s. II d. C. una inscripción de Megalópolis atestigua la celebración de ambas fies$\operatorname{tas}^{29}$, pero Pausanias no habla de las Lykaia como una fiesta que se celebre en su época en el Liceo o, al menos, eso hace pensar la expresión "allí celebraban antiguamente los Juegos Liceos"30. Así mismo, el Periegeta comenta que las basas ya no sostienen estatuas, lo que habla de un deterioro del culto. Es posible, como sugirió en su momento Fougères y recoge Jost (1985: 185) que para época de Pausanias las Lykaia se hubie-

25. FGrHist 239 A 10 y 17.

26. $I G \mathrm{~V} 2,436,437$ y 438 ; Moretti $1953, \mathrm{n}^{\circ} 40,44,45,51$ y 53 .

27. Strab. VIII $8,2$.

28. $I G \mathrm{~V} 2,515$ b, lín. 31.

29. $I G \mathrm{~V} 2,463$

30. Paus. VIII 38, 5: $\tau$; $\delta \varepsilon ; \alpha \varsigma \rho \xi \alpha l^{\circ}$ ov $\tau \omega^{\circ} v \Lambda v \kappa \alpha i n \omega \nu$ $\eta \varsigma^{\circ} \gamma \circ \nu \tau 0 ; \nu \alpha \varsigma \gamma \omega^{\circ} v \alpha \varepsilon \varsigma \eta \tau \alpha v^{\circ} \theta \alpha$. sen trasladado desde el Liceo hasta el centro de Megalópolis, donde se había construido una réplica exacta del santuario del Liceo (Jost 1994: 229). No obstante, dado que en la ciudad no existe un estadio y no se hace mención de una nueva localización en ninguna de las inscripciones conservadas, nada puede decirse con razonable precisión. Lo más probable es que continuaran los ritos y fiestas en la cima del Liceo, y al mismo tiempo en la réplica del santuario construida en Megalópolis. El doblete cultual, la duplicación ritual, refuerza la sacralidad del monte y del culto en él llevado a cabo y, al trasladarlo, Megalópolis expresa su deseo de compartir la gracia que el dios dispensa a sus fieles

En una carrera por instrumentalizar los juegos y equipararlos al resto de las competiciones clave de Grecia, las normas de las Lykaia imitaron hasta cierto punto a las de Olimpia. No se sabe a ciencia cierta con qué regularidad se celebraban las Lykaia en época arcaica, pero parece que en época clásica tenían lugar cada cuatro años, al igual que los Juegos Olímpicos o los Píticos (Hughes 1986: 190). La fecha exacta de la celebración también se desconoce, aunque suele encuadrarse en un arco temporal que abarca desde febrero a finales de la primavera. La duración es, así mismo, incierta. El comando arcadio de la Anábasis, dirigido por Jenias, se detiene tres días en Peltas para celebrar la fiesta nacional con un sacrifico y unos juegos atléticos, al igual que se hacía en el monte Liceo. No obstante, es difícil precisar hasta qué punto un ejército en campaña puede mantener el calendario religioso de su pueblo, de modo que poca precisión puede darse a la duración y temporalidad de la fiesta.

También desconocemos qué tipo de pruebas atléticas incluían, aunque para época de Píndaro estaban 
instauradas al menos la carrera simple ( $\delta \rho o ́ \mu o \varsigma)$, la do-

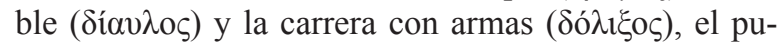
gilato, la lucha, el pancracio y, posiblemente, el pentathlón ${ }^{31}$. Posteriormente, queda constancia además de carreras de caballos ${ }^{32}$ y sabemos que existían concursos separados para hombres y jóvenes (Jost 1985: 267). El premio solía ser un trípode de bronce ${ }^{33}$.

Situado en el centro del valle, el hipódromo conserva una estructura muy cuidada: en el extremo sur, orientadas E-O, Kourouniotis pudo distinguir cuatro hileras de gradas para los espectadores. Más abajo, cerca del punto donde debía de tener lugar la salida de los competidores (salida que no ha sido encontrada), también destacó una línea de asientos de mejor factura, lo que hace pensar que estarían reservados para las autoridades arcadias. A 265 metros al norte, en el otro extremo del valle, Kourouniotis (1909: 189-190) advirtió sobre la existencia de dos basas cilíndricas separadas por 60 metros entre ellas y por 30 del talud E-O. Quizá podrían corresponderse con el comienzo de la pista, aunque es dudoso (Jost 1985: 182). Al este del hipódromo, cuando el valle se ensancha, se encuentra el estadio, paralelo al hipódromo (Jost 1985: 182).

Para impresionar a los visitantes y albergarlos cómodamente se levantaron un buen número de edificios anexos. En el lado norte se conserva una habitación cuadrada con dos basas de piedra y una cisterna. Al sureste, al pie de un montecillo que linda con el hipódromo, Kourouniotis (1909: 187-192) habla de un pórtico de 70 x $11 \mathrm{~m}$., posiblemente construido en el s. IV, como la mayor parte de las edificaciones anexas (Jost 1985: 182). No se conservan las columnas con las imágenes de los vencedores, pero Pausanias menciona una profusión de ellas ${ }^{34}$. Por la expresión del Periegeta es posible suponer que la desaparición de estas estatuas se produjo en época antigua, posiblemente en el último cuarto del s. II a. C. (Jost 1998: 256).

Al suroeste del pórtico se halla un edificio cuya funcionalidad se desconoce. Cuadrado (6, 80 x 5, $80 \mathrm{~m}$.) tiene forma de hemiciclo al interior y cuenta con una columnata jónica que se cree de época romana. A 50 metros al noroeste de este edificio romano, al pie de un montecillo, se conserva en muy buen estado una fuente (Kourouniotis 1909: 196-198; Jost 1985: 183). Cerca se descubrieron dos basas de estatuas y un fragmento

31. Pind. Ol. VII $84 ;$ Nem. X 48.

32. Sobre las pendientes de la montaña algunos observadores del siglo pasado advirtieron de la existencia de restos de carriles excavados en la roca (Cfr. Fougères 1904: 1433).

33. Pind. Ol. VII $84 ;$ Nem. X 48.

34. Paus. VIII 38,5 . de epígrafe en mal estado de conservación con los nombres de los Licaónidas ${ }^{35}$.

$\mathrm{Al}$ suroeste de la planicie se encuentra un gran $x e$ non cuadrangular de $38 \times 20 \mathrm{~m}$. que se ha datado a finales del s. IV. Los muros que se conservan (sector noreste) alcanzan los 2 metros de altura. Se ha supuesto que es un hotel por su estructura de patio con múltiples habitaciones, en una de las cuales se encontraron dos estelas del s. IV con las listas de vencedores de las Lykaia $^{36}$ aunque, en principio, parece que no era esta su localización original y que las piezas estaban descontextualizadas (Jost 1985: 182). Una escalera adosada al muro pertenecía a un edificio bastante más antiguo del que apenas quedan piedras en pie. (Fig. 3).

Kourouniotis (1909: 198-199) propuso que en el espacio comprendido entre el pórtico, el xenon y la fuente, donde se podían ver algunos capiteles dóricos, debería hallarse el santuario de Pan, rodeado por un bosque sacro, del que habla Pausanias cuando describe el área ${ }^{37}$. Este arqueólogo realizó algunas catas sin resultado. La localización es hipotética, ya que la descripción de Pausanias no es muy clara, así que es posible que el templo se situara en otro lugar. También, como apunta Jost (1985: 183), es probable que un santuario de Pan en un alsos no fuera una construcción monumental (quizá, ni siquiera fuera una construcción), lo que explicaría la ausencia de restos destacados.

Al tiempo que se producen cambios físicos en el Liceo, se reorganizan sus símbolos para convertirlos en elementos exportables. Las imágenes de sus dos deidades, Zeus Lykaios y Pan, cuyos sacerdotes se turnaban en la presidencia de las $L y k a i a^{38}$, se acuñan en el anverso y el reverso de las monedas que emite la Confederación Arcadia primero y la propia Megalópolis después (Jost 1985: 184 y 475; Fougères 1904: 1435). No obstante, la iconografía de ambas deidades se adapta a los nuevos tiempos. No se pretende exportar la imagen de una Arcadia sangrienta, bañada por la sangre de los sacrificios humanos. Esa imagen le había resultado útil a los parrasios para definirse frente a sus enemigos, pero ya no servía a los intereses de Megalópolis, que quería presentarse como la cabeza de una Arcadia civilizada. Así, la cara de Zeus se acuña en el anverso coronada de laureles, de perfil, como en muchas otras representaciones griegas. En el caso de Pan, cuando aparece en el reverso (en ocasiones se elige otro modelo, concretamente el águila de Zeus sobre un rayo), apenas se

\footnotetext{
35. $I G \mathrm{~V} \mathrm{2,} 548$.

36. $I G \mathrm{~V} 2,549$ y 550 .

37. Paus. VIII $38,5$.

38. $I G \mathrm{~V} \mathrm{2,550.}$
} 
Fig. 3. Restos del xenon del Monte Liceo (Fotografía de la autora).

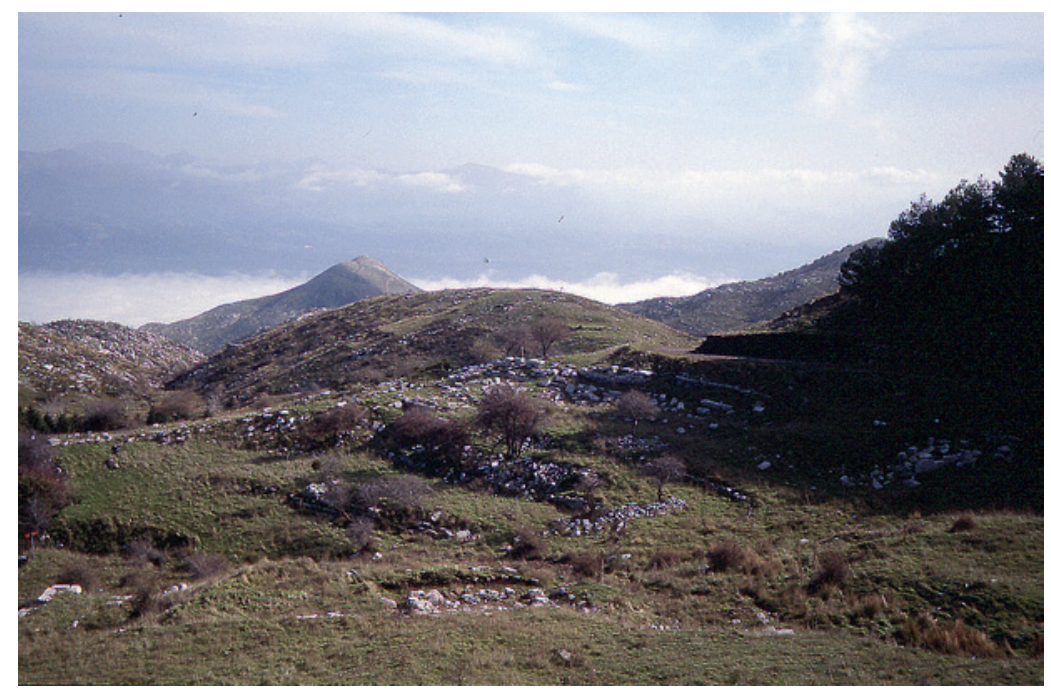

reconoce al dios cabra en el jovenzuelo apolíneo con dos pequeños cuernos sobre la cabeza a modo de reminiscencias de un pasado que interesaba pulir y adaptar (Williams 1965). (Fig. 4).

En el ágora de Megalópolis, como dije, se alzó una réplica del santuario al Zeus Lykaios que contaba con una imagen de mármol del Pan Sinois ${ }^{39}$, advocación de origen figalio, pues el Pan Sinois era uno de los habitantes divinos del templo de Basas. Las imágenes de Pan no son extrañas al culto del dios, pero la del Pan Sinois es de mármol, un material bastante alejado de las posibilidades económicas de los modestos pastores y cazadores que constituían el grupo principal de los fieles del dios antes de su expansión por Grecia a raíz de las Guerras Médicas (Cardete 2004a). La presencia de Pan al lado de Zeus es un signo identitario más, pues Pan era una de las deidades locales más entroncada con la religiosidad popular (Borgeaud 1979). Ahora bien, cabe preguntarse si las raíces de dicha asociación eran profundas o simplemente políticas y/o superficiales.

Jost (1985: 268, n. 5 y 474) defiende que la relación entre Pan y Zeus en el Liceo se debe en gran parte a la "naturaleza del paisaje", caracterizado por las cimas montañosas en las que tan a gusto se siente Zeus y, al tiempo, Pan encuentra a sus fieles: pastores y cabreros. Creo que, por una parte, esta interpretación simplifica en exceso una conexión religiosa demasiado repetida para ser accidental. Pan no sólo tiene un papel importante en la cima del Liceo, sino también en sus contrafuertes, en el santuario de Berecla, y en Licosura, otro centro clave del paisaje religioso parrasio y, además, es
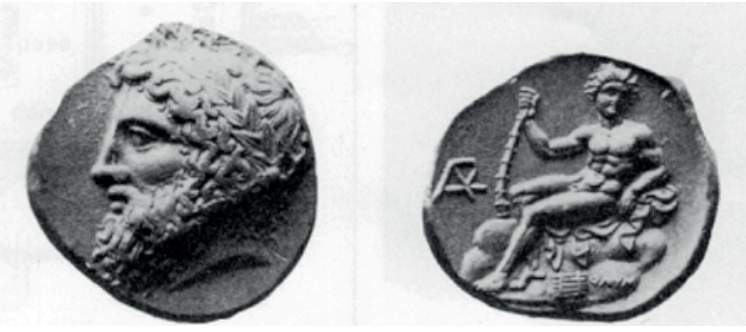

Fig. 4. Pan (reverso) y Zeus Liceo (anverso) en una moneda de la Confederación Arcadia (Boardman1997b, fig. 37).

una figura recurrente en el macizo de Basas, tan conectado cultural y políticamente con el Liceo, con presencia destacada no sólo en el mismo santuario de Basas sino también en el mito de la Deméter Melena, donde funciona como servidor de Zeus y benefactor de los figalios $^{40}$. Por otra parte, la hipótesis de Jost parte de un concepto de paisaje como escenario dado al que los actores se adaptan. Sin embargo el paisaje es un concepto mucho más amplio, puesto que constituye una red de significados que refleja las complejidades sociales, económicas, políticas, ideológicas, simbólicas, culturales... de la sociedad (Tilley 1994: 34; Cardete 2005b).

Considero, por tanto, que Zeus y Pan, al menos en el ámbito parrasio, se relacionaban estrechamente entre sí, aunque la naturaleza de dicha relación sea difícil de precisar. Fougères (1904: 1436) los convirtió en una pareja de contrarios: Zeus era el dios que se transformaba en lobo y Pan, el primer dios del santuario, se encargaba de proteger a los pastores contra los lobos y

39. Paus. VIII 30, 2-3.

40. Paus. VIII 42, 2-4. 
cuidar de la salud del ganado. Burkert (1983: 92-93), por su parte, cree que ambas deidades encarnan la antítesis entre la agresión y la sexualidad o, al menos, entre el orden y la vida salvaje, antítesis que preside todo el culto del Liceo. Por mi parte, creo que la pareja Zeus Liceo-Pan forma parte de la construcción étnica fomentada desde Megalópolis. La fuerza que el Liceo tenía como símbolo quedaba reforzada con la presencia de un dueto de dioses étnicos: el Zeus del Liceo no se parece en sus atribuciones mitológicas al resto de advocaciones que de este dios circulaban por Grecia y Pan, como acabo de decir, es una deidad autóctona que sólo a partir de las Guerras Médicas y gracias a la mediación de Atenas deja las fronteras arcadias para extenderse por otras partes de Grecia (Cardete 2004a).

Tampoco debemos olvidar el teriomorfismo de ambos dioses, que redunda en la tan ansiada antigüedad del culto. Zeus Lykaios no se representa nunca con rasgos físicos lobunos, pero sus fieles, cuando entran en relación estrecha con el dios, se convierten en licántropos y sólo la expiación de la mancha les permite recuperar su naturaleza humana y ser admitidos por la comunidad y por el dios. Por su parte, Pan es una cabra. $\mathrm{Su}$ iconografía puede dividirse en dos grandes modelos, pero en ambos los cuernos cápridos son un atributo incuestionable. El primer modelo es el más arcaizante. En él descubrimos a un Pan mitad cabra mitad humano. Generalmente la parte superior es humana y las extremidades inferiores de cabra o macho cabrío, aunque también se conocen ejemplos, como el conocido bronce de Lusos, en el que el dios presenta cabeza y piernas de cabra con torso y brazos humanos o en los que la única parte animal es precisamente la cabeza, como en la cratera ática del pintor de Pan (Allard Pierson Museum de Ámsterdam, nos. 2117), fechada entre 500-490 a. C., en la que este dios persigue a un cabrero. El segundo modelo responde a tendencias más antropomorfas como las que emplean las ya nombradas monedas de la Confederación Arcadia. En ocasiones incluso resulta difícil descubrir la identidad del dios cabra, pues se le representa como un muchacho apuesto y musculoso (siguiendo el canon del Doríforo) pero, eso sí, con unos diminutos cuernos sobre la cabeza que recuerdan su procedencia (Jost 1985: 464-466; Beazley 1968 y 1978; Boardman 1997a; Hild 1904: 296-302).

Tanto interesó a Megalópolis apropiarse de la figura de Pan y convertirlo en bandera que la imagen de bronce del Pan Escolitas se trasladó desde la colina que le daba nombre hasta el centro cultual de Megalópolis $^{41}$, desde el exterior del núcleo cívico al corazón

41. Paus. VIII 30,6. mismo de la fuerza ciudadana (Moggi y Osanna 2003: 436). Además, Pan, con su inseparable siringa, aparece también esculpido en una mesa en el recinto de las Grandes Diosas, acompañado de dos Horas y un Apolo Citaredo que, según Pausanias, forman parte del grupo de los primeros dioses ${ }^{42}$ pues no en vano Pan llegó a ser tenido por el dios más antiguo para los $\operatorname{arcadios}^{43}$. Incluso llega a rebasar las fronteras megalopolitanas para alcanzar el suelo tegeata, donde se conoce un altar a Pan Lykaios y otro a Zeus Lykaios ${ }^{44}$ y algunos restos de santuarios ${ }^{45}$.

Otra muestra de cómo las elites megalopolitanas emplearon la creencia religiosa como arma de manipulación ideológica con fines étnicos es el caso de la apropiación del santuario del Apolo Parrasio por parte de la nueva ciudad.

A cinco kilómetros al sureste de la cima de San Elías, en el camino que une Isoma y Ano-Kariés, en la pequeña colina de Liacos, Kourouniotis realizó algunas catas y encontró vestigios antiguos interpretados como la antigua Cretea de la que habla Pausanias, en la que la tradición arcadia situaba el nacimiento y la crianza de Zeus y en la que se construyó el santuario de Apolo Parrasio $^{46}$, rodeado de un bosque sagrado ${ }^{47}$. Este santuario extraurbano destaca sobre todo por la fiesta que describe Pausanias y que incluía procesión y sacrificios. Como muchos autores han defendido siguiendo las tesis de Polignac, uno de los elementos clave de los santuarios extraurbanos es la procesión que los unía, con motivo de una fiesta, con el territorio de la aldea o de la ciudad, fomentando la unidad y solidaridad de grupo a través del refuerzo a la identidad compartida (Polignac 1984; Cardete 2003 y 2005, 83-87). En este caso, que se mantuviera la procesión después del cambio en el patrón de poblamiento que supuso la fundación de Megalópolis a costa de las comunidades de los parrasios y menalios es un indicador de que Megalópolis vio en ella un medio de mantener las antiguas tradiciones en el nuevo marco político para no desarraigar a los habitantes de la zona. De hecho, el epíteto cultual de la deidad, Parrasio, lo vincula directamente con su comunidad y, gracias a la procesión y la fiesta, también con Megalópolis, a la que le interesaba mantener excelentes relaciones con las comunidades absorbidas.

42. Paus. VIII $31,3$.

43. Dioni. Halicar. I 32, 3.

44. $I G \mathrm{~V} 2,93$.

45. Paus. VIII 53,11.

46. Paus. VIII 38, 2.

47. Sobre la problemática alrededor del emplazamiento de Cretea ver resumen en Hejnic (1961: 20); Jost (1985: 186 y 1998: 255) y Cardete (2005 ${ }^{\mathrm{a}}$ : 198). 
La ceremonia es especialmente significativa, pues une, no sólo simbólica sino también físicamente, el campo y la ciudad, los dos elementos básicos de la identidad ciudadana. La parte religiosamente álgida del sacrificio, la muerte de la víctima, se llevaba a cabo en el ágora de la nueva ciudad, bendecida por el rito. Pero el elemento más social del sacrificio, el banquete comunitario, que reunía a la población y fomentaba la cohesión de grupo, se llevaba a cabo en el santuario, en el espacio tradicionalmente destinado a ello ${ }^{48}$.

Megalópolis significaba el cambio, pero sus dirigentes eran conscientes de que debían presentarlo bajo ropajes de continuidad. El culto del Apolo Parrasio y la procesión que organizaba su fiesta contribuyó a asentar un nuevo paisaje en el que las distancias físicas se minimizaban a través de los simbolismos religiosos de base identitaria. El paisaje no tiene por qué entenderse como un continuum geológico; muchas veces, de hecho, la explicación a un paisaje se encuentra a miles de kilómetros de distancia. Además, la procesión a la montaña desde el núcleo cívico y el sacrificio de una víctima perteneciente al ámbito de lo salvaje funcionan como una especie de tributo de la comunidad, que se aventura en zonas de no-civilización para regresar transformada, asentadas aún más las normas sociales (Buxton 2000: 100).

¿Podemos decir, tras estas reflexiones, que los parrasios funcionaron como una etnia, que construyeron una idiosincrasia y la opusieron al Otro (cambiante dependiendo del momento) para protegerse de sus ataques? Creo que podemos decir que el Liceo fue el eje de la identidad parrasia antes de que la comunidad tribal cayera en manos de Megalópolis. Es posible que dicha identidad deviniera en un sentimiento étnico como modo de cohesionar a un grupo amenazado, especialmente por Esparta, el enemigo natural de todas las comunidades de la frontera suroeste. Pero lo que parece claro es que el entramado míticoétnico parrasio que ha llegado hasta nosotros no respondía a las necesidades de las comunidades que rodeaban al Liceo, aun pudiendo basarse en ellas, sino a las aspiraciones panarcadias de Megalópolis. Si Megalópolis recurrió a aunar creencia con identidad fue porque sabía que dicha unión podía favorecer sus intereses. Y si no lo hizo con éxito en el pasado sí lo ha conseguido en el presente, ya que es su imagen de Arcadia la que ha llegado hasta nosotros y nosotros continuamos reproduciendo.

48. Paus. VIII 38,8 .

\section{BIBLIOGRAFÍA}

ALTY, J. (1982): "Dorians and Ionians", JHS 102: 1-14. ANDERSON, B. (1991): Imagined communities: reflections in the origins and spread of nationalism, London.

BARTH, F. (ed.) (1976): Los grupos étnicos y sus fronteras, México.

BEAZLEY, J. D. (1978): Attic Black-Figure VasePainters, New York.

- (1968): Attic Red-Figure Vase-Painters, London.

BOARDMAN, J. (1997a): "Pan", en LIMC VIII (1) y VIII (2): 923-941 y 612-635. Paris.

- (1997b): The Great God Pan: the survival of an image (Walter Neurath Memorial Lecture 1997), London.

BORGEAUD, P. (1979): Recherches sur le dieu Pan, Genève.

BRADLEY, R. (1991): "Monuments and places" en GARWOOD, P., JENNINGS, D., SKEATES, R. and TOMS, J. (eds.), Sacred and profane: 135-140. Oxford.

BRIANT, O. (1989): "Histoire et idéologie. Les Grecs et la "décadence perse" en MACTOUX, M. M. et GENY, E. (eds.), Mélanges Pierre Lévêque 2. Anthropologie et société : 33-47. Paris.

BURKERT, W. (1983): Homo Necans: the anthropology of Ancient Greek sacrificial ritual and myth, Los Angeles.

BUXTON, R. G. A. (2000): El imaginario griego: los contextos de la mitología, Madrid.

CARDETE DEL OLMO, M. C. (2005a): Paisajes mentales y religiosos: la frontera suroeste arcadia en épocas arcaica y clásica, Oxford.

- (2005b): "La polis como articulación social: el caso arcadio", Gerión 23 (1): 81-99.

- (2004a): "La construcción de un mito: el encuentro entre Pan y Filípides en el Partenio", en HERNÁNDEZ GUERRA, L. y ALVAR EZQUERRA, J. (eds.), Actas del XXVII Congreso Internacional GIREA-ARYS IX, Jerarquías religiosas y control social en el mundo antiguo, Valladolid 7-9 Noviembre 2002: 215-222. Valladolid.

- (2004b): "Ethnos y etnicidad en la Grecia clásica", en CRUZ ANDREOTTI, G. y MORA SERRANO, B. (eds.), Identidades étnicas-identidades politicas en el mundo prerromano hispano: 17-29. Málaga.

- (1993): "Identidad y religión: el santuario de Apolo en Basas", Studia Historica, Historia Antigua 21: 47-74.

CARTLEDGE, P. (1993): The Greeks: a portrait of self and others, Oxford. 
DOW, S. (1937): "Athenian Decrees of 216-212 B. C.", HSCP 48: 120-126.

DUKE, P. (1998): "Ethnicity: past and present", Cambridge Archaeological Journal, 8 (1): 119-121.

EIDHEIM, H. (1976): "When ethnic identity is a social stigma”, en BARTH, F. (ed.), Los grupos étnicos y sus fronteras: 50-74. México.

EMBERLING, G. (1997): "Ethnicity in complex societies: archaeological perspectives", Journal of Archaeological Research 5 (4): 295-344.

ERIKSEN, T. H. (1993): Ethnicity and nationalism. Anthropological perspectives, London.

FOUGÈRES, G. (1898) : Mantinée et l'Arcadie orientale, Paris.

— (1904): "Lykaia", DA: 1432-1437.

HALL, E. (1989): Inventing the barbarian. Greek selfdefinition through tragedy, Oxford.

HALL, J. M. (2002): Hellenicity. Between ethnicity and culture, London.

- (1998): "Discourse and praxis: ethnicity and culture in Ancient Greece", Cambridge Archaeological Journal 8 (2): 266-269.

- (1997): Ethnic identity in Greek antiquity, Cambridge.

- (1995): "Approaches to ethnicity in the early Iron Age of Greece", en SPENCER, N. (ed.) Time, tradition and society in Greek archaeology. Bridging the "Great Divide": 6-17. London.

HARTOG, F. (1980): Le miroir d'Hérodote: essai sur la representation de l'autre, Paris.

HEJNIC, J. (1961): Pausanias the perieget and the archaic history of Arcadia, Praga.

HILD, J. A. (1904): “Pan”, DA: 296-302.

HUGHES, D. (1986): Human sacrifice in Ancient Greece (D. Phil. Thesis), Ohio.

HUNTINGTON, S. P. (1997): El choque de civilizaciones y la reconfiguración del orden mundial, Barcelona.

JENKINS, R. (1997): Rethinking ethnicity: arguments and explorations, London.

JONES, S. (1998): "Ethnic identity as discursive strategy: the case of the Ancient Greeks", Cambridge Archaeological Journal 8 (2): 271-273.

- (1997): The archaeology of ethnicity: constructing identities in the past and in the present, London.

JONES, S. and GRAVES-BROWN, P. (1996): "Introduction. Archaeology and cultural identity in Europe", en GRAVES-BROWN, P., GAMBLE, C. and JONES, S. (eds.), Cultural identity and Archaeology: the construction of European communities: 1-24. London.

JOST, M. (1985): Sanctuaries et cultes d'Arcadie, Paris.

- (1994): "The distribution of sanctuaries in civic space in Arkadia", en ALCOCK, S. and OSBORNE,
R. (eds.), Placing the gods. Sanctuaries and sacred space in Ancient Greece: 216-230. Oxford.

- (1999): "Les schémas de peuplement de l'Arcadie aux époques archaïque et classique", en NIELSEN, T. H. and ROY, J. (eds.), Defining Ancient Arkadia, Symposium April 1-4, 1998, Acts of the Copenhagen Polis Centre, Vol. 6: 192-247. Copenhagen.

JOST, M.; CASEVITZ, M. et MARCADÉ, J. (ed., trad. y notas) (1998): Pausanias. Description de la Grèce, Tome VIII, Livre VIII, L'Arcadie.

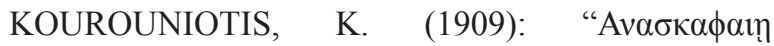

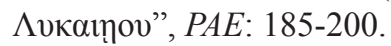

LÉVY, E. (1984): "Naissance du concept de barbare", Ktema 9: 5-14.

MALKIN, I. (1998): The returns of Odysseus: colonization and ethnicity, Berkeley.

MOGGI, M. e OSANNA, M. (ed., trad. y notas) (2003): Pausania. Guida della Grecia. Libro VIII. $L$ 'Arcadia, Milano.

MORETTI, L. (1957): Olympionikai. I vincitori negli antichi agoni olimpici, Roma.

MORGAN, C. (1997): "The archaeology of sanctuaries in Early Iron Age and archaic ethne. A preliminary view", en MITCHELL, L. and RODHES, P. J. (eds.), The development of the polis in Archaic Greece: 168-198. London.

- (1991-1992): "Ethnicity and early Greek states: historical and material perspectives", Proceedings of the Cambridge Philological Studies 37: 131-163.

MORRIS, I. (1998): "Words and things", Cambridge Archaeological Journal 8 (2): 269-270.

NIELSEN, T. H. (1996a): “A survey of dependant poleis in classical Arkadia”, en HANSEN, M. H. and RAAFLAUB, K. (eds.), More studies in the ancient Greek polis, Papers from the Copenhagen Polis Centre 3: 63-105. Stuttgart.

- (1996b): “Arkadia. City-ethnics and tribalism", en HANSEN. M. H. (ed.), Introduction to an inventory of Polis, Acts of Copenhagen Polis Centre 3: 117-163.

- (1996c): "Was there an Arkadian confederacy in the fifth century B.C.?", en HANSEN, M. H. and RAAFLAUB, K. (eds.), More studies in the ancient Greek polis, Papers from the Copenhagen Polis Centre 3: 39-61. Stuttgart.

- (1997): "Triphylia. An experiment in ethnic construction and political organisation", en NIELSEN, T. H. (ed.) Yet more studies in the Ancient Greek polis, Papers from the Copenhagen Polis Centre: 129-162. Stuttgart.

- (1999): "The concept of Arkadia- the people, their land and their organisation", en NIELSEN, T. H. and 
ROY, J. (eds.), Defining Ancient Arkadia, Acts of the Copenhagen Polis Centre 6: 16-88. Copenhagen.

- (2002): Arkadia and its poleis in the Archaic and Classical Periods, Göttingen.

NIELSEN, T.H. y ROY, J. (1998): "The Azanians of northern Arkadia", Classica et mediaevalia 2: 5-44.

OVENSEN, J. (1983): "Man or beast? Lycanthropy in the Naga Hills", Ethnos 1-2: 5-25.

PASCUAL GONZÁLEZ, J. (2001): "Identidades y fronteras en Grecia central", en LÓPEZ BARJA, P. y REBOREDA MORILLO, S. (eds.), Fronteras $e$ identidad en el mundo griego antiguo, III Reunión de Historiadores: 241-263. Santiago de Compostela-Vigo.

PARK, Ch. C. (1994): Sacred worlds: an introduction to geography and religion, London.

POLIGNAC, F. de (1984): La naissance de la cité grecque, Paris.

PRONTERA, F. (2003): Otra forma de mirar el espacio: Geografía e Historia en la Grecia antigua, Málaga.
RENFREW, C. (1998): "From here to ethnicity", Cambridge Archaeological Journal 8 (2): 275-277.

RENFREW, C. y MESKELL, L. (2001): "From social to cognitive archaeology: an interview with Colin Renfrew", Journal of Social Archaeology, 1 (1): 13-34.

ROY, J. (1972): "Tribalism in Southwestern Arcadia in the Classical Period", Acta Antiqua Academiae Scientiarum Hungaricae 20: 43-51.

SHENNAN, S. J. (ed.) (1994): Archaeological approaches to cultural identity, London.

SIAPKAS, J. (2003): Heterological ethnicity: conceptualizing identities in ancient Greece, Uppsala.

SMITH, A. D. (2000): The nation in history. Historiographical debates about ethnicity and nationalism, Oxford.

- (1986): The ethnic origins of nations, Oxford.

TILLEY, Ch. (1994): A phenomenology of landscapes. Places, paths and monuments, Oxford.

WILLIAMS, R. T. (1965): The Confederate Coinage of the Arcadians in the fifth century B. C., New York. 